\section{Ionizing Radiations}

J. S. Strettan. Pp. viii +173 illustrated. Oxford, London, etc.: Pergamon Press. 1965. 20s.

This volume is written primarily for Science Sixth Forms and Technical Colleges and assumes a certain basic knowledge of electricity, electronics and mathematics. With this proviso, it should prove to be a useful introduction for postgraduate students whose research involves the use of radioactive isotopes or other ionizing radiations: it should also be of value to D.M.R. students as additional reading to widen their appreciation of the subject; and it may help public health students in an aspect of their work which is going to become more important in the future.

In a book of this size some sacrifices are essential, but on the whole a good balance has been struck between the academic side of the subject and its practical applications. Omissions are rare but one must comment that it was surprising not to find more stress being laid on the universal distribution of radiation in our daily lives and of how man has to live with radiations in addition to harnessing and making use of them: the basic data on which the ICRP have made their recommendations of the Maximum Permissible Doses should surely have found a place in a book which otherwise is a definite contribution towards helping students to see ionizing radiations in their true prospective. Further criticism of the biological aspects would be unjust in a subject which is changing so rapidly and providing that the reader bears in mind the purpose of the book I can gladly recommend it to the groups mentioned.

\section{A Search for Genetic Effects of High Natural Radioactivity in South India}

H. Gruneberg, G. S. Bains, R. J. Berry, L. Riles, C. A. B. Smith and R. A. Weiss. Pp. vii + 59 illustrated. M.R.C. Special Report Series 307. London: H.M.S.O. 1965. $11 \mathrm{~s}$.

This report is a study on the black rat population of a strip of Kerala coast where the background radiation is relatively high owing to thorium-rich monazite deposits. It was hoped that it might yield knowledge of the somatic or genetic effects of chronic low-level exposure to radiation, but the failure of these workers to discover positive evidence of genetic effects of low-level radiation in this careful work suggests that further studies of this kind in areas of high background radiation are unlikely to yield the data which they are at first promised. The problems facing these workers were considerable: even in this high background area the dose rate only yields $1 \mathrm{r}$. per reproductive life of each rat and the effects on genetic variance may be obscured by phenotypic or environmental variance: in addition there are the commoner problems of difficulties of sampling this natural population. The discussion of the negative correlation is admirable.

One periodically hears comment that important information should come from studies of this well-known beach and this detailed report will interest those studying the genetic effects of radiation.

\section{The Physiology of Blood Platelets}

AARON J. MARCUS, and MARJORIE B. ZuCKer. Pp. $x+162$. New York and London: Grune and Stratton. 1965. \$7.00.

In this concise volume the authors have concentrated in 13 chapters practically all the recent work on platelets dealing chiefly with the biochemistry, morphology, and function of platelets in health and disease. The literature has been so exhaustively reviewed that there are no less than 43 pages of references included. The references are numbered and at times almost a whole line of numbers appear in the text and not always with the authors names which makes the reading somewhat tedious.

Included under platelet structure there is a short chapter on the electron microscopy of platelets which also covers the principles of technique. The only figure in the book is in this chapter and is an electron micrograph of human platelets.

There are also short chapters on studies on platelet survival and platelet transfusion.

This book is a veritable mine of detail and perhaps because it is so packed with facts it should be considered more of a reference book and as such is a classic work and particularly recommended to all those interested in and working in the various fields of platelet research.

\section{Atlas of Orthopaedic Exposures}

Toufick NicOla. Pp. 135 with 281 Figures.

Baltimore: Williams and Wilkins.

Edinburgh and London: E. \& S. Livingstone. 1966. $80 \mathrm{~s}$.

An atlas is a volume of maps to enable you to find youre way. This atlas of Orthopaedic Exposures certainly? does that. The beautifully produced illustrations drawn by the author contain all essential structures to identify one's approach, the important structures to avoid also being shown. Each operative exposure has with it the indications, the steps in the operation, and comments on any point of special difficulty. Alternative approaches (seven in the case of the hip joint) are given which should cover most Orthopaedic Surgeon's tastes. Although most of the illustrations are very easy to understand, I found it difficult to operate on the spine with all the approaches being from the under surface: I felt that the illustrations should all have been inverted. I found only one surgical error, this being a straight incision across the flexure of the wrist in the exposure of the carpal tunnel, although four pages later a diagram of incisions in the palm shows the correct incision with a kink at the flexure. It is obvious that this book has been written by a practical surgeon with a wealth of experience, who is able to draw what the surgical eye sees as being important. At four pounds it is very reasonably priced, and should be in every Orthopaedic Operating theatre and on every Orthopaedic trainee's bookshelf. 